\title{
Towards a European Space Agency
}

Since April 1 this year we have awaited the establishment of the European Space Agency (ESA). The new single organisation will take over the functions of the three existing bodiesESRO, ELDO and the ESC*-to become the NASA of Western Europe. ESA will be responsible for running not only the scientific and application satellite programmes of ESRO but also the three new ventures decided a year ago by ten European space nationsthe Spacelab orbital laboratory, the Ariane launcher and the Marots maritime satellite. Each of these three new programmes will be developed under the respective sponsorship of Germany, France and the UK. The rules of participation in the programmes will of ESA. As before, a participating country will have work allocated to it by the Agency in proportion to the amount of cash it subscribes. But now member-states will also have the right to contribute such sums as they feel necessary, and to opt out of specific Agency programmes which they don't find attractive.

The creation of ESA has been progressively delayed throughout this year. The ten European ministers will meet again this week in Paris, but a French government source said last week that there would be no decision until mid-October. Indeed, it is absolutely impossible to foresee what could happen next month. There may be another postponement, but it is hoped that ESA should be settled before the end of the year.

The delay is caused by a fight for the leadership of ESA between the two most important contributing countries. also be changed by the new convention

France and Germany have both proposed a candidate as first general manager of the organisation. France is also trying to obtain the participation of the other member states to the cost of the French Guiana Space Centre, which became the launching range for the Ariane rockets. Unexpected events like the sudden death of President Georges Pompidou and the following election campaign have also contributed to the delay.

The new French government hasn't decided much about space affairsapart from signing the Memorandum of Understanding for the joint development of the Aerosat satellites by Europe and the United States.

On current thinking, the French government should define its space policy in early October at a special council of the ministers concerned. Some official sources say it will closely analyse the space report, and the Ariane project will certainly be questioned. The former government always thought that the heavy launcher was to be "the keystone of the European space policy", considering the political and economical value of the application satellites. More than 3,500 million francs have been spent to duplicate the US heavy rocket that failed when the Europa 2 rocket blew up in the Atlantic. Now France and Germany require an American launcher to put the Symphonie communications satellite into orbit in December of this year. But the US State Department imposed such limita. tions to the use of this experimental satellite that its interest will be significantly reduced.

Now comes the second and decisive stage for the European rocket. In May,

Spacelab: first flight planned for 1980.

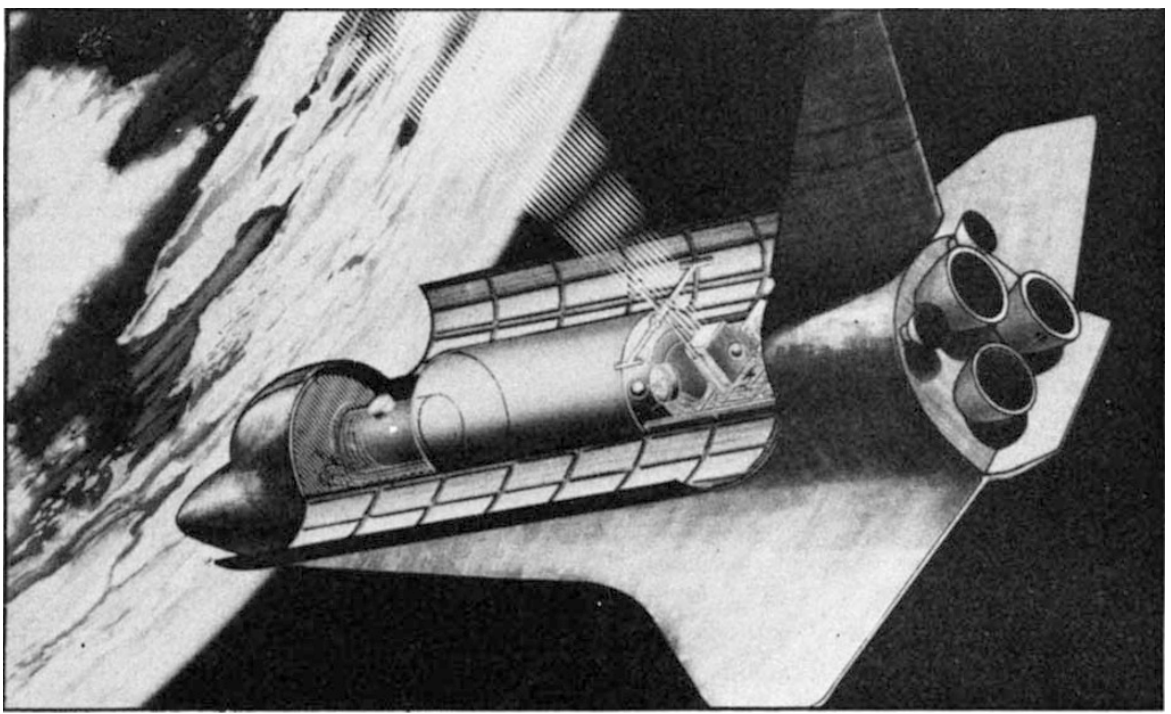

1973, France proposed to jump a step with Ariane, a more powerful launcher able to place a $750 \mathrm{~kg}$ payload into geostationary orbit, which could be developed before the end of the decade. France picked up at least $65 \%$ of Ariane costs, which are currently budgeted at about 2,500 million francs for the development only. Ten European countries, including the U.K., are participating in this programme. Tooling up, long-term supplies and engine ground testing are now under way, and the industrial team has been selected recently.

Meanwhile, last June, the French government withheld authorisation for the Centre National d'Etudes Spatiales (the technical and financial manager of Ariane) to conclude the long-term contracts of development with the main contractors. The government needs to think carefully before acting because the programme necessitates more and more spending during the next three years at the same time as the other European space activities also begin to be more costly. In spite of all these new expenses the government don't want to increase the space budget; recent reports from the French Ministry of Industry are very clear about this. In such circumstances the CNES may be obliged to reduce, postpone or even to cancel some of its activities although usually France considers that European expenses take priority.

Nevertheless, the Ariane programme could be in danger. The 200-ton threestage launcher will be the largest rocket built in Europe. But it will be relatively expensive and its market seems less important than expected. A joint study by French and Germans anticipated 35 to 50 launches in ten years $(1980-90)$. But it was never published, and the specifications for the launch range consider only two firings per year during the same period, i.e. less than half the forecast.

The real reason for the difficulties is a political, economical and cultural one: the French desire to build "the launcher of European independence". But it is not certain that the new government will follow its predecessor on this policy. President Valery Giscaid d'Estaing has based his policy on change, and on the evidence of the past three months he has a habit of making surprising decisions. For the present government to drop the idea of backing the launcher would be the worst thing possible for the French aerospace industry.

Despite these troubles, the other programmes are running well. Spacelab, which will also be a long-term develop- 
International Magnetospheric Explorer $(I M E)$ : to be placed in orbit in 1977.

ment with significant spendings, is going on. This 400 million dollar programme will be a truly international space venture under the leadership of Europe. Developed by 10 countriesall 10 members of ESRO except Sweden but with Austria--the Spacelab will be a part of NASA Space Shuttle Transportation System. European industrial and technical teams are in permanent contact with NASA officials over the development of this spacecraft, which will be completely dependent on the Space Shuttle Orbiter.

It is a versatile manned space laboratory in which scientists and engineers with only a short training as astronauts will be able to live and work for periods of one week to one month in weightlessness. The crew will perform different tasks: scientific missions, Earth resources and weather surveys, communications and other technology experiments. The orbital laboratory has two main parts: a pressurised module connected by an airlock to the Orbiter crew cabin and a pallet which supports instruments exposed to the vacuum of space.

NASA has ordered two Spacelabs from ESRO. The first flight of Spacelab is planned for April 1980, with the seventh flight of the Shuttle, on a mission not yet defined. More than 200 experiment proposals have already been received by ESRO from the European scientific community for this flight.

The next two European scientific satellites will be in space within a year. The COS-B satellite will be launched in April or May 1975 to study gamma rays, and the GEOS satellite will be put into the geostationary orbit in September, 1976, to investigate plasma distribution, energetic particles and electromagnetic fields.

In December, 1976, NASA will launch the International Ultraviolet Explorer satellite (IUE), a joint US-UK project in which ESRO participates. The next project will also be a cooperative one between NASA and ESRO. The ISEE satellite (formerly IME-D) is due for launch in September, 1977, with a brother American satellite from the same launcher to study the magnetosphere. For mid-1979, ESRO is preparaing the highly eccentric lunar occultation satellite (EXOSAT) that will map the X-ray sources.

Since 197013 scientific mission pronosals have been submitted to ESRO, but only one or two will be retained in early 1976 for development. All these missions could be realised with the Spacelab or free flyer satellites. Twothirds of them are cooperative projects

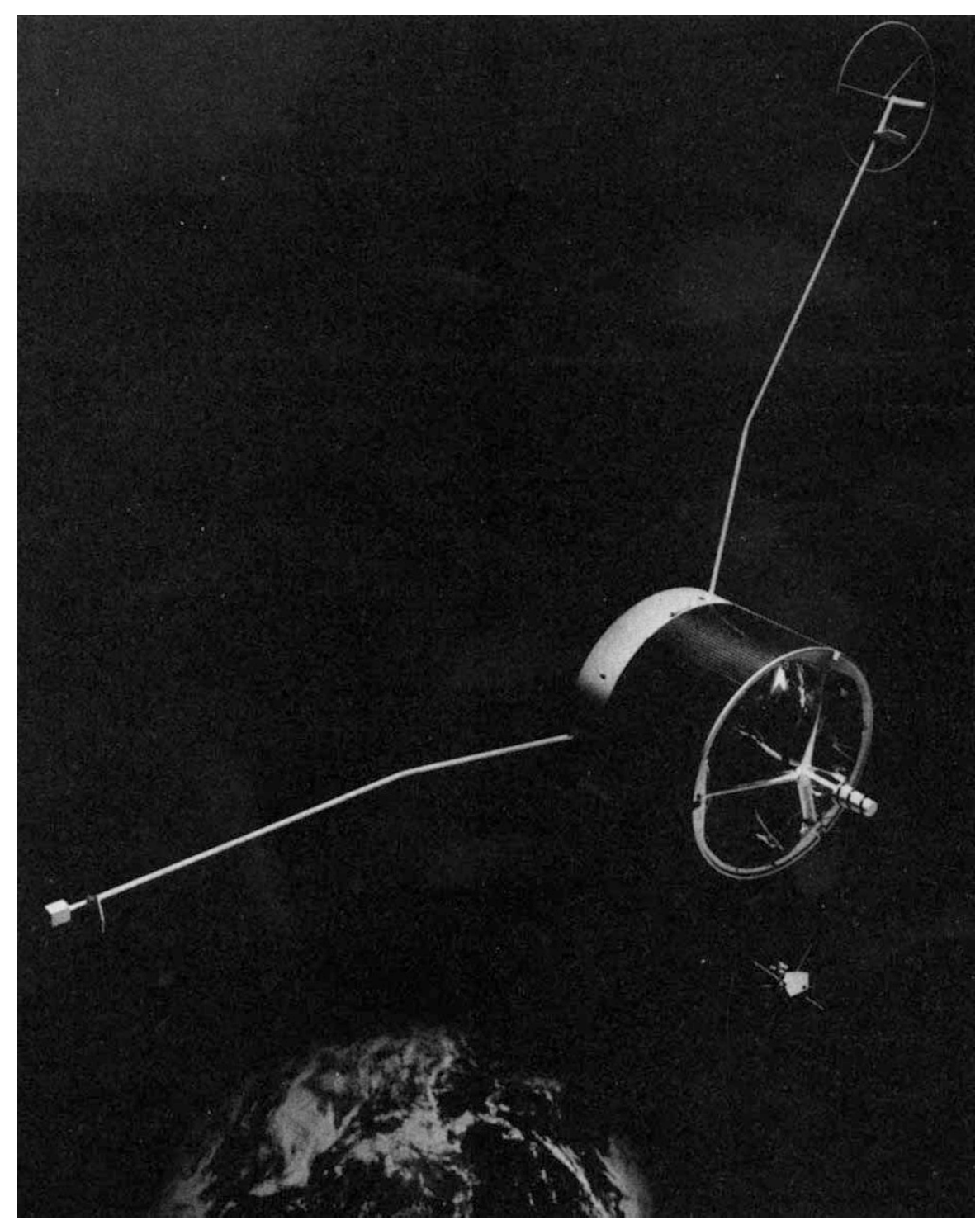

with NASA. Nine are devoted to infrared, ultraviolet and $X$ radiation studies of the Sun and the sky. Three others are more impressive projects including the first probe to make observations from out of the plane of the ecliptic.

There is also a Pioneer-Jupiter orbiter probe and the interception of Comet Encke by the end of 1980 to proceed with the first close study of thesem ysterious space objects. Another proposal is an astrometry mission to chart more than 30,000 stars down to magnitude 17 with a precision 10 times better than the existing references. The feasibility of this project will be discussed at a special colloquium to be held next month at Frascati (Italy).

Among the application programmes, the meteorological satellite (Meteosat) will be put into geosynchronous orbit in December, 1976, to participate in the Global Atmospheric Research Program of the World Weather Watch. Three other experimental satellites are due for launch close to the end of 1977 to prepare the operational systems of the 1980s. The OTS satellite will pave the way for the European Communications Satellite (ECS) designed to provide space links for intra-European telephony, telegraphy, telex and TV relay for the European Broadcasting Union. The aeronautical satellite (Aerosat) will be the first step towards a world-wide air traffic control and communications satellite system. And the maritime satellite (Marots) will carry out experiments involving communications between ground and merchant ships to prepare the future IMCO operational system to cover the seas and the oceans of Earth. All these new European satellites-like the seven built over 10 years by ESRO-will be launched by American rockets from the United States.

*ESRO is the European Space Research Organisation; ELDO is the European Launcher Development Organisation formerly responsible for the launcher Europa 2, and ESC is the European Space Conference, i.e. the forum for decisions by the European science ministers.

-From the staff of La Recherche 